\title{
Zooming in on dynamics of marine microbial communities in the phycosphere of Akashiwo sanguinea (Dinophyta) blooms
}

Seung Won Jung ( $\sim$ diatoms@kiost.ac.kr)

Korea Institute of Ocean Science and Technology https://orcid.org/0000-0002-7473-7924

Joonsang Park

Korea Institute of Ocean Science and Technology

Junsoo Kang

Korea Institute of Ocean Science and Technology

Hyun-Jung Kim

Korea Institute of Ocean Science and Technology

Hyung Min Joo

Korea Polar Research Institute

Donhyug Kang

Korea Institute of Ocean Science and Technology

Hyojeong Seo

Pukyong National University

Sunju Kim

Pukyong National University

Min-Chul Jang

Korea Institute of Ocean Science and Technology

Kyunwoo Lee

Korea Institute of Ocean Science and Technology

Seok Jin Oh

Korea Institute of Ocean Science and Technology

\section{Sukchan Lee}

Sungkyunkwan University

Taek-Kyun Lee

Korea Institute of Ocean Science and Technology

\section{Research}

Keywords: Akashiwo sanguinea HABs, environmental change, endoparasitic Amoebophrya sp., microbial communities, nucleocytoplasmic large DNA viruses, network analysis 
Posted Date: March 13th, 2020

DOl: https://doi.org/10.21203/rs.3.rs-17150/v1

License: (c) (i) This work is licensed under a Creative Commons Attribution 4.0 International License. Read Full License 


\section{Abstract}

Background: Characterising ecological relationships between viruses, bacteria, and phytoplankton in the ocean are critical to understanding the ecosystem, yet these relationships are infrequently investigated together. To understand the dynamics of microbial communities and environmental factors in harmful algal blooms (HABs), we examined the environmental factors and microbial communities during Akashiwo sanguinea HABs in the Jangmok coastal waters of South Korea by metagenomics.

Results: Specific bacterial communities showed synergistic and antagonistic relationships with $A$. sanguinea bloom. Endoparasitic dinoflagellate Amoebophrya sp. 1 controlled the bloom dynamics, as an increase in their abundance was correlated with HAB decline. In the nucleocytoplasmic large DNA viruses, abundance of Pandoraviridae increased following an increase in HAB. Operational taxonomic units and environmental factors associated with $A$. sanguinea were also visualized by network analysis: $A$. sanguinea-Amoebophrya sp. 1 ( $\mathrm{r}=0.81$, Time-lag: 2 day) and $A$. sanguinea-Pandoravirus dulcis $(0.64,0$ day) relationships showed close association. $A$. sanguinea-dissolved organic carbon and -dissolved inorganic phosphorus relationships were also very closely correlated (each 0 day time-lag, respectively).

Conclusions: Microbial communities and the environment dynamically and complexly changed in $A$. sanguinea bloom, and a rapid turnover of microorganisms could respond to ecological interactions. $A$. sanguinea bloom dramatically changes the environments through their exudation of dissolved carbohydrates by autotrophic processes, followed by changes in microbial communities involving hostspecific viruses, bacteria, and parasitoids. Thus, microbial communities in HAB ecology are composed of various organisms and they interact in a complex way. Therefore, to interpret their ecosystem, the complex reactions among various microorganisms should be studied rather than studying a simple 1:1 reaction, such as a prey-predator interaction.

\section{Background}

In ecology, phytoplankton are considered a double-edged sword[1]. Although phytoplankton is an essential component of the marine ecosystem, with multiple roles in matter cycling[2], a few phytoplankton taxa form harmful algal blooms (HABs), which can adversely impact marine ecosystems and human health[3]. A vast majority of the known HABs are dinoflagellates[4], among which, Akashiwo sanguinea causes frequent blooms world-wide[5,6]. A. sanguinea produces surfactants that saturate the feathers of marine birds with water and cause severe hypothermia[7] and have also been related to fish kills and marine mammal strandings[8]. However, the environmental changes caused by these strategies in dissolved organic matters and specific nutrient sources of this bloom are still poorly understood.

Marine microbial communities are diverse and support other marine organisms. Microbial communities, including viruses, bacteria, fungi, and some parasitic algae, have the potential to impact population dynamics of HAB organisms[9]. Viruses are the most common biological entities in the marine environment, which contribute significantly to the flux of energy and matter, and influence 
biogeochemical cycling[10]. Nucleocytoplasmic large DNA viruses (NCLDVs) infect both animals and unicellular eukaryotes[11]. Members of the Phycodnaviridae family are large icosahedral NCLDVs that are mostly known to infect eukaryotic algae[12]. However, each viral family has not yet been assigned a species-specific host group. For example, Mimiviridae infect Acanthamoeba and other protists serve as natural hosts[13], but members of this group have also been found to infect various phytoplankton species, recently. Thus, role of each group of the NCLDVs in host-specific infection is yet to be elucidated[13,14].

Interactions between phytoplankton and bacteria are important in shaping their environment, and consequently, the biogeochemical cycles[15]. Phytoplankton relies on bacteria to remineralise organic matter back to its inorganic substituents[16]. Recently, specific bacterial phylotypes have been detected in association with different microalgae. Yang et al.[17] reported species-specific relationships between bacterial communities and $A$. sanguinea bloom. In eukaryotic parasitoids, Amoebophrya sp. kills its host and controls the dinoflagellate bloom[18]. Amoebophrya sp. has relatively short generation time and high prevalence in nature[19,20]. Studies on the interaction between Amoebophrya sp. and A. sanguinea bloom as host are in the laboratory[19]; however, ecological species-specific host-parasitoid interactions are yet to be elucidated.

Interactions among microbial communities in an ecosystem are very complex. Therefore, assessment of the changes in environmental characteristics and their interaction with the microorganisms in $A$. sanguinea bloom can increase our understanding of the microbial communities. With the advancement of metagenomic next-generation sequencing (mNGS) technology, a large volume of sequencing data have been analysed and baseline information regarding genetic traits has been developed. In addition, many ecological studies have used mNGS to estimate changes in population dynamics and communities[21]. Also, the new technologies for studying aquatic microbial diversity require smaller volume and nanograms of DNA[22]. To explore changes in environmental characteristics and microbial communities in the phycosphere of $A$. sanguinea bloom and to estimate the potential control mechanisms for $A$. sanguinea bloom, we investigated the ecological phenomena when $A$. sanguinea was bloomed in the Jangmok Bay Time-series Monitoring Site (JBTMS). In particular, we conducted an intensive monitoring plan (i.e., daily sampling) for understanding dynamics of microbial communities and environments and established an $100 \mathrm{~L}$-scale in-door microcosm to mimic a real ecosystem. Microcosm and/or mesocosm studies can clarify the effect of variation in environmental and biological factors on the system, and provide an important link between laboratory and field data[23].

\section{Results}

\section{Environmental characteristics during Akashiwo sanguinea bloom}

Variations were observed in the environmental characteristics of JBTMS from June 2016 to June 2017 (Supplementary Fig. 1). A. sanguinea bloom sustained for 44 days; it developed on October $31^{\text {st }}$ and declined on December 13 $3^{\text {th }}, 2016$ (Fig. 1). During this blooming period, the mean abundance of $A$. 
sanguinea was 542 cells $\mathrm{mL}^{-1}$, with a maximum abundance of 2,935 cells $\mathrm{mL}^{-1}$ on November $18^{\text {th }}$; the water temperature gradually decreased, and $A$. sanguinea bloom rapidly declined below $16{ }^{\circ} \mathrm{C}$ (after November $21^{\mathrm{st}}$ ). Dissolved silica (DSi) concentrations remained between 21.18 and $30.67 \mu \mathrm{M}$, and did not show a significant correlation with the abundance of $A$. sanguinea. Dissolved inorganic nitrogen (DIN) concentrations rapidly decreased at the beginning of $A$. sanguinea bloom and remained between 1.19 and $2.87 \mu \mathrm{M}$. Dissolved inorganic phosphorus (DIP), dissolved organic carbon (DOC), and chlorophyll a concentrations showed similar changes following $A$. sanguinea bloom and were significantly correlated with change in $A$. sanguinea abundance.

Daily monitoring of the JBTMS from November $14^{\text {th }}$ to December $26^{\text {th }}, 2017$, showed that the dominant phytoplankton was Bathycoccus prasinos (Chlorophyta) (Supplementary Fig. 2). We also observed that the water temperature was lower in 2017 than in 2016 , rising over $16^{\circ} \mathrm{C}$ for only two days in 2017. pH and dissolved oxygen (DO) concentration were also lower in 2017 than in 2016. DIN, DIP, and DOC concentrations did not change with B. prasinos abundance. Changes in the DIP concentration showed no significant correlation with $B$. prasinos. The in-door microcosm experiment showed environmental characteristics similar to those of the JBTMS in 2016 (Supplementary Fig. 3). A. sanguinea abundance decreased gradually with decreasing water temperature. Ammonia, DIP, and DOC concentrations and total bacterial abundance decreased with decreasing $A$. sanguinea abundance, and increased again because of the substance release caused by the destruction of $A$. sanguinea cells in a closed environment.

\section{Species-specific bacterial community during $A$. sanguinea bloom}

mNGS results for bacterial community in JBTMS are summarised in Supplementary Table 1. In 2016, the bacterial community was classified into four groups at $73 \%$ similarity by non-metric multidimensional scaling (nMDS) analysis (Fig. 2a). Group I was associated with "before $A$. sanguinea bloom" (4 ${ }^{\text {th }}$ and $31^{\text {st }}$ October). This group comprised communities of Alpha-proteobacteria (73\%), Flavobacteriia (13\%), Gamma-proteobacteria (8 \%), and other bacteria. Group II and III were associated with "during $A$. sanguinea bloom" (November $7^{\text {th }}$ to $28^{\text {th }}$ ), wherein Flavobacteriia increased rapidly to $39.94 \%$. Group IV was associated with "after $A$. sanguinea bloom" (29 ${ }^{\text {th }}$ November to $26^{\text {th }}$ December). In this group, abundance of Gamma-proteobacteria (13\%) increased from that of Group III. In 2017, bacterial community was divided into two groups at $70 \%$ similarity by nMDS analysis (Fig. 2b). Group I was associated with "dominance of $B$. prasinos" (14 ${ }^{\text {th }}$ November to $13^{\text {th }}$ December), and the group also comprised Alpha-proteobacteria (44\%), Flavobacteriia (20\%), Gamma-proteobacteria (7 \%), and others (28\%). In group II (After decrease of B. prasinos abundance, December $19^{\text {th }}$ and $26^{\text {th }}$ ), Alphaproteobacteria rapidly increased to a proportion of $80 \%$.

The number of operational taxonomic units (OTUs) and alpha diversity showed a trend similar to that in the read counts and varied according to the period (Supplementary Table 1). The most abundant bacterial OTUs in 2016 belonged to Alpha-proteobacteria (9 OTUs), Gamma-proteobacteria (7), Flavobacteriia (11), and other bacterial species, including Beta-proteobacteria (1) and Actinobacteria (2) (Fig. 3, Supplementary Fig. 4). Before A. sanguinea bloom (Group I), eight bacterial OTUs were common 
species, and Cribrihabitans marinus (Alpha-proteobacteria) was dominant at $53.91 \%$ (relative abundance). During $A$. sanguinea bloom (Group II and III), 18 bacterial OTUs were common species, and uncultured Alpha-proteobacterium (OTU \#2) and C. marinus (Alpha-proteobacteria; $21.01 \%$ and 13.83\%, respectively), and Tenacibaculum aiptasiae and Polaribacter marinivivus (Flavobacteriia; $10.95 \%$ and $10.41 \%$, respectively) were dominant with an accumulated proportion of $56.2 \%$. In particular, the changes of uncultured bacterium (OTU \#2) and $A$. sanguinea cells were significantly correlated $(r=0.90, p<$ 0.001). After $A$. sanguinea bloom (Group IV), 22 bacterial OTUs were common species, including $C$. marinus, and Amylibacter ulvae (Alpha-proteobacteria; $7.98 \%$ and $15.94 \%$, respectively), Mesonia algae (Flavobacteriia; $16.61 \%$ ), and Methylophilus methylotrophus (Beta-proteobacteria; $3.14 \%$ ). In 2017, the most abundant bacterial OTUs belonged mainly to Alpha-proteobacteria (7), Gamma-proteobacteria (6), Flavobacteriia (11), and other bacteria including Beta-proteobacteria (1) and Actinobacteria (1) (Fig. 3, Supplementary Fig. 4). During the dominance of B. prasinos (Group I), C. marinus (20.77\%), A. ulvae (11.71\%), and Euzebya tangerine (25.83\%, Actinobacteria) were the pre-dominant species in 16 common bacterial OTUs. After the decrease in abundance of B. prasinos (Group II), A. ulvae, Lentibacter algarum, and Planktomarina temperata (Alpha-proteobacteria; $40.71 \%, 11.49 \%$, and $21.37 \%$, respectively), and $E$. tangerine $(5.52 \%)$ were the dominant species in the nine common bacterial OTUs.

\section{Potential NCLDVs infection of $A$. sanguinea bloom}

The mNGS results for NCLDVs of both JBTMS (2016 and 2017) and in-door microcosm are summarised in Supplementary Table 2 and Supplementary Table 3, respectively. In 2016, the most abundant NCLDV OTUs belonged mainly to Phycodnaviridae (9 OTUs), Pandoraviridae (3), Poxviridae (6), and Iridoviridae (1). According to nMDS analysis of NCLDVs composition in 2016, NCLDVs were clustered in four groups at $79 \%$ similarity (Fig. 2c). Before A. sanguinea bloom (Group I), the major NCLDVs groups at family level were Poxviridae (55\%), Phycodnaviridae (25\%), Pandoraviridae (20\%), and others (including Mimi- and Irido-viridae) (<1\%). During $A$. sanguinea bloom (Group II and III), Pandoraviridae increased rapidly to 61 $\%$. In particular, Pandoravirus salinus and Pandoravirus dulcis were positively correlated with $A$. sanguinea abundance ( $r=0.67$ and $r=0.66, p<0.01$, respectively) (Supplementary Fig. 5). After $A$. sanguinea bloom (Group IV), Pandoraviridae decreased to $31 \%$, while Phycodnaviridae and Poxviridae relatively increased to $32 \%$ and $36 \%$, respectively; however, Pandoraviridae increased again when Heterocapsa triquetra (Dinophyta) appeared (Fig. 4a). In 2017, the most abundant NCLDV OTUs mainly belonged to Phycodnaviridae (11 OTUs), Pandoraviridae (4), Poxviridae (6), Iridoviridae (1) and Mimiviridae (1). NCLDVs were clustered in three groups (Fig. 2d). During the dominance of $B$. prasinos (Group I), Phycodnaviridae and Pandoraviridae were dominant, adding up to $89.59 \%$ of the total relative abundance. In Phycodnaviridae, $H$. akashiwo virus 1 and $P$. globosa virus were strongly and positively correlated to $B$. prasinos abundance, while Ostreococcus lucimarinus virus 2,0 . lucimarinus virus OIV5, and $O$. tauri virus 2 were negatively correlated to $B$. prasinos abundance (Supplementary Fig. 5). In Pandoraviridae, Pandoravirus salinus, Pandoravirus dulcis, and an unidentified Pandoravirus were positively correlated with changes in B. prasinos abundance (Supplementary Fig. 5). However, after the decrease in abundance of B. prasinos (Group II and III), Phycodnaviridae rapidly increased to $96 \%$ (Fig. 4b). In the in-door microcosm, NCLDVs showed patterns similar to those of JBTMS in 2016. In particular, 
Pandoraviridae (mainly, Pandoravirus salinus and Pandoravirus dulcis) decreased as $A$. sanguinea cells decreased (Fig. 4c and Supplementary Fig. 5). Phycodnaviridae (mainly, Heterosigma akashiwo virus1 and Phaeocystis globosa virus) showed a pattern opposite to that of $A$. sanguinea cells.

\section{Endoparasitic dinoflagellate dynamics during $A$. sanguinea bloom}

To explore co-occurrence patterns, focusing primarily on potential parasitic interactions between endoparasitic dinoflagellate Amoebophrya sp. ex. A. sanguinea, we assessed the relationship between Amoebophrya sp. (Syndiniales) and A. sanguinea in JBTMS and the indoor-microcosm. mNGS results of eukaryotic (18S rDNA) communities in JBTMS and the microcosm are summarised in Supplementary Table 4 and Supplementary Table 5, respectively. In 2016, Amoebophrya sp. 1 trends were strongly associated with those of $A$. sanguinea bloom in the JBTMS (Fig. 5a). Moreover, dinospores of Amoebophrya sp. 1 changed similarly to A. sanguinea cells (Fig. 5a). After A. sanguinea disappeared, Heterocapsa triquetra emerged, and another OTU (Amoebophrya sp. 2) was detected (December $26^{\text {th }}$, Fig. 5a). Other Syndiniales seldom appeared during A. sanguinea bloom. In 2017, Amoebophrya sp. 1 was barely detected in seawater, but Amoebophrya sp. 2 increased rapidly when $H$. triquetra emerged (Fig. 5b). In the in-door microcosm, Amoebophrya sp. 1 (same sequences of Amoebophrya sp.1 as that in JBTMS) in seawater increased for 3 days, but rapidly decreased after 4 days and was barely detected after 6 days (Fig. 5c). Dinospores of Amoebophrya sp. 1 also showed similar patterns to those of $A$. sanguinea.

\section{Network analysis during A. sanguinea bloom in 2016 and no-bloom in 2017}

Network analyses of microbial communities were focused on A. sanguinea in 2016 and B. prasinos in 2017 and exhibited distinct associated interaction with specific microbial communities and environmental factors (Supplementary Tables 6-8, Fig. 6). The 2016 network had significantly correlated biological and environmental factors with 67 nodes and 577 edges (Fig. 6a). A. sanguinea association networks identified factors that were highly correlated to specific OTUs, such as bacteria (19 OTUs), NCLDVs (6), and parasitic dinoflagellates (2), and environmental factors (5) (Fig. 6b). Our association network supports the paradigm that $A$. sanguinea bloom is regulated by both parasitic dinoflagellate (Amoebophrya sp. 1, r=0.81, and time-lag: 2 day) and NCLDVs (Pandoravirus dulcis and Pandoravirus salinus, $r=0.64$ and $0.61,0$ day delay time, respectively). In networks with bacterial communities, uncultured Alpha-proteobacterium (OUT \#2) was highly and positively correlated (0.93) with 0 day timelag, but other specific bacterial species in Gamma-proteobacteria and Beta-proteobacteria were negatively linked. In network with environmental factors, strong positive connectivity of DOC $(0.86,0$ day) and DIP (0.98, 0 day) may reflect $A$. sanguinea-selective interactions.

The 2017 network showed biological and environmental factors with 80 nodes and 824 correlations (Fig. $6 \mathrm{c})$, and this network was more diversely correlated than the 2016 network. Association networks of $B$. prasinos were correlated with 74 specific OTUs (11 phytoplankton OTUs, 6 ciliates, 2 parasitic dinoflagellates, 27 bacteria, and 28 NCLDVs) and 9 environmental factors (Fig. 6d). In networks with bacterial communities, Alpha-proteobacteria (-0.78, 0 day), Gamma-proteobacteria (-0.60, 0 day), Beta- 
proteobacteria $(-0.76,2$ day), and Flavobacteriia $(-0.63,2$ day) were negatively correlated at different time lags with $B$. prasinos, and Actinobacteria were only positively correlated (0.71) at 0 day time-lag. The $B$. prasinos network indicated connections of diverse microbial communities with interconnected niches. The network of $B$. prasinos was not correlated with Amoebophrya sp. 1 and mildly correlated with Pandoravirus dulcis, while $B$. prasinos was strongly and positively correlated with Cowpox virus OTU $(0.86)$ at 0 day time lag, and this interaction may reflect $B$. prasinos-selective infection. Moreover, $B$. prasinos showed strong positive connectivity with Strombidium ciliate, which may reflect competition and feeding pressure. In the network with environmental factors, $B$. prasinos negatively correlated with DOC $(-0.74,2$ day) and showed relatively low correlation with DIP $(0.61,2$ day $)$ as compared with the $A$. sanguinea network in 2016.

\section{Discussion}

HABs are a common ecological issue in coastal waters globally[1,3]. We show that $A$. sanguinea abundance initially increased by taking up DIN from the surrounding waters, and DIP and DOC concentrations strongly and immediately increased with the development of $A$. sanguinea bloom. This could be because of the dissolved carbohydrate $(\mathrm{DCHO})$ being released by $A$. sanguinea cells. In marine systems, evidence for strong correlations between $\mathrm{DCHO}$ concentrations and phytoplankton biomass were found in oceanic surface waters[24,25,26]. DCHO production by marine phytoplankton depends on the species, growth stage, and environmental conditions[27,28,29]. Urbani et al.[30] reported biodegradability of DCHO released by Thalassiosira pseudonana and Skeletonema costatum (centric diatoms). Thus, $A$. sanguinea bloom markedly increases biological carbon export into the surrounding waters. A. sanguinea bloom is dominant worldwide in cold seasons $[5,6]$. In this study, A. sanguinea bloom rapidly decreased when water temperature was below $16^{\circ} \mathrm{C}$ (Fig. 1). Our microcosm experiment results proved that $A$. sanguinea growth was inhibited at water temperature below approximately $15^{\circ} \mathrm{C}$. Matsubara et al.[31] reported that the temperature range for growth of $A$. sanguinea is very wide (10-30 $\left.{ }^{\circ} \mathrm{C}\right)$, while Du et al.[6] mentioned that the temperature range for growth of $A$. sanguinea is very narrow $\left(11-12{ }^{\circ} \mathrm{C}\right)$. Therefore, in our study, temperature below $16^{\circ} \mathrm{C}$ could be a limiting factor for the growth of the bloom.

According to Yang et al.[5], bacterial abundance greatly increased in the $A$. sanguinea bloom area during a bloom in the Xiamen sea, and DO concentration dropped as a result of bacterial decomposition of $A$. sanguinea. However, bacterial abundance was not significantly associated with $A$. sanguinea bloom and did not affect DO levels in our study (Fig. 1). Nevertheless, certain bacterial communities were closely related to $A$. sanguinea bloom (Fig. 3, Supplementary Fig. 4). Specific bacteria, such as $P$. marinivivus and uncultured Alpha-proteobacterium (OUT \#2) may have a symbiotic association in A. sanguinea bloom, while A. ulvae, M. algae, and L. syltensis may be inhibited in the HABs. Hence, it is important to elucidate the ecological role of specific bacteria associated with $\mathrm{HABs}[32,33]$. Our results are in accordance with results from previous reports[34], which state that phytoplankton harbour (habitat "phycosphere") specific bacterial communities. We found that bacterial species composition varied at different growth stages of A. sanguinea (Fig. 3). Antibacterial metabolites are produced by some phytoplankton[33], which possibly 
inhibit certain bacterial species. These antibacterial substances are particularly associated with DCHO excreted from a phytoplankton cell[27]; thus, the physiological flexibility of bacteria may support their colonization. In previous studies, algicidal bacteria have shown a sudden increase in the presence of HABs[35]. Mayali and Azam[36] suggested that algicidal bacteria may affect HAB dynamics, as their abundance increases with the decline of algal blooms. In our study, the most common algicidal bacteria belonged to Gamma-proteobacteria and Bacteroidetes (Supplementary Table 9), and no sign of HAB control by algicidal bacteria was observed: Alteromonas and Pseudoalteromonas in Gammaproteobacteria as well as Saprospira and Cytophaga in Bacteroidetes (i.e., common algicidal bacteria) had low abundance (or not detected), and their abundance did not increase after the decline of $A$. sanguinea bloom. Therefore, no specific bacteria in this study showed the potential to control the $A$. sanguinea bloom.

Our results revealed that Pandoraviruses were positively correlated to $A$. sanguinea bloom, indicating that Pandoraviruses can potentially infect $A$. sanguinea. For further studies, similar interactions between species-specific NCLDVs and $A$. sanguinea blooms could be investigated. In the in-door microcosm, Pandoraviruses were closely related to $A$. sanguinea bloom based on their similarity with the pattern of Pandoraviruses in the field. Pandoraviruses are mainly known to infect amoebas[37], but sufficient studies have not been performed on different hosts; thus, there is no substantial evidence to determine whether Pandoraviruses have the potential to infect $A$. sanguinea or whether this behaviour is normal for the viruses in lower water temperature periods in any host. It has been previously proposed[38] that Pandoraviruses are highly evolved Phycodnaviruses[39]. Phycodnaviridae showed low relative abundance during $A$. sanguinea bloom, which increased after the bloom disappearance. Thus, our results revealed that the distribution of Pandoraviruses is closely related to the distribution of $A$. sanguinea bloom, which is the key to understanding the reason underlying termination of $A$. sanguinea bloom. Recently, unlike the "killing the winner hypothesis"[40], Silveira and Rohwer[41] founded the "piggybackwinner hypothesis", which states that viruses potentially infect hosts, until they liquefy in time to the outside environment. Therefore, further study is required to identify specific infection mechanisms of Pandoraviruses against $A$. sanguinea and to estimate the ecological role of these viruses in nature.

An endoparasitic dinoflagellate, Amoebophrya sp. has the capacity to efficiently control populations of their dinoflagellate hosts, and infection, as this parasitoid spreads rapidly through dense dinoflagellate populations, facilitating the decline of the dinoflagellate bloom[42]. Many marine phycologists $[9,19,20,43]$ have reported that Amoebophrya sp. can easily infect $A$. sanguinea. mNGS has revealed the enormous genetic diversity of Amoebophrya-like organisms within the marine alveolate group II[43,44]. In this study also, there were genetic divergences among several Amoebophrya spp.[i.e., Amoebophrya sp. 1 (OTU \#24) and Amoebophrya sp. 2 (OTU \#14)]. OTUs of Amoebophrya sp. 1 in sea water (free living Amoebophrya sp. 1), in A. sanguinea (infected dinospores of Amoebophrya sp.) in the JBTMS, and in the in-door microcosm verified the evident control of $A$. sanguinea blooms by Amoebophrya sp. 1 (Fig. 5). This can be explained by the short generation time of Amoebophrya[20]. The ecological role of hostspecific Amoebophrya infection might have a greater impact on the population dynamics of toxic bloomforming dinoflagellates than by the microzooplankton grazing (Supplementary Fig. 6); Amoebophrya can 
potentially eliminate an entire host population within a few days[45]. This study has revealed a natural phenomenon wherein an endoparasitic dinoflagellate controls their host. However, the study did not consider Amoebophrya sp. killing mechanisms. Thus, further experiments are needed on host-parasitoid interactions to estimate the ecological role of Amoebophrya, and to study how various Amoebophrya species coexist in a nature.

The network analysis revealed that the $A$. sanguinea bloom in 2016 was associated with specific microbial communities and some environmental factors and showed differentiation of network results of 2017. A major strength of this study is the high-resolution sampling approach. Day-to-day sampling of an A. sanguinea bloom spanning is a great resource for understanding the fine scale dynamics of the lifecycle of the bloom. In 2016, connected partners with A. sanguinea blooms included taxa (OTUs) from all trophic positions (i.e., infections, parasites, phototrophs, and heterotrophs). Environmental factors, such as water temperature, salinity, DO, DIP, and DOC can immediately respond to $A$. sanguinea bloom (0-day time-lag). Thus, network analyses showed changes in DIP and DOC concentration derived from DCHO released by $A$. sanguinea bloom. Moreover, specific NCLDVs (including Pandoraviruses) and endoparasitic dinoflagellate (Amoebophrya sp. 1) with positive associations have been found to regulate $A$. sanguinea bloom. In previous studies $A$. sanguinea bloom has been negatively associated with competition, niche partitioning, and grazing $[46,47]$. Thus, the high connectivity displayed by some microbial communities and environmental factors with $A$. sanguinea bloom suggest similarity in their ecological properties (symbiosis and inhibition as well as infection etc.). Our study shows the value of frequent sampling to evaluate community responses and microbial interactions among protists by reinforcing recent ideas about rapid dynamics and the importance of parasites.

On the basis of these results, we propose three stages of interactions between environmental characteristics and microbial communities in A. sanguinea bloom via a conceptual diagram (Fig. 7): (i) "before $A$. sanguinea bloom": diatoms and Alpha-proteobacteria were common phytoplankton and bacterial groups, respectively. Low abundance of Amoebophrya sp. 1 was observed in this stage. The predominant NCLDV group was Poxviridae. In environmental characteristics, most parameters (particularly DIN) were detected to be higher than those in the other stages; (ii) "during A. sanguinea bloom": $A$. sanguinea bloom showed marked changes in the environmental characteristics (which were exported into the surrounding waters), followed by changes involving species-specific virus, bacteria, and parasitoids. A. sanguinea abundance initially increased by taking up DIN and DIP from the surrounding waters, but changes in DIP and DOC concentrations were strongly positive correlated with changes in HABs. $A$. sanguinea bloom harboured and promoted specific bacterial populations. In particular, host-specific bacterial group (Flavobacteriia increased rapidly) that remineralise extracellular products from $A$. sanguinea participates in biogeochemical cycling and play an important part in the dynamics of microbial communities. Specific NCLDVs, Pandoraviridae, increased following an increase in $A$. sanguinea abundance, particularly during bloom peaks. Endoparasitic dinoflagellate, Amoebophrya sp. 1, has attracted attention regarding its roles in trophic interactions; (iii) "After $A$. sanguinea bloom": when $A$. sanguinea bloom was terminated, water temperature was below $16{ }^{\circ} \mathrm{C}$, and most environmental characteristics showed little changes. Succession of common phytoplankton groups occurred from $A$. 
sanguinea to diatoms (Pseudo-nitzschia delicatissima and Skeletonema marinoi-dorhnii complex species) and Heterocapsa triquetra (dinoflagellate). Variations in bacteria and NCLDV groups were observed, such as relative increase in Gamma-proteobacteria and Phycodnaviridae, respectively. Amoebophrya sp. 1 rapidly decreased with the termination of $A$. sanguinea bloom.

\section{Conclusions}

In the present study, the following new evidence to support the interaction between environmental characteristics and microbial communities in $A$. sanguinea bloom was obtained: (i) DIP and DOC concentrations rapidly and strongly shifted with $A$. sanguinea bloom; (ii) a specific bacterial community associated with $A$. sanguinea bloom showed ecological symbiosis, inhibitory role; they might provide a suitable environment for a diverse subset of bacteria from a "Phycosphere" perspective; (iii) Pandoraviridae may have an important role in controlling $A$. sanguinea population, despite being known to infect mainly amoeba; (iv) Amoebophrya sp. may control $A$. sanguinea bloom dynamics with low water temperature, as the increase in its abundance is correlated with HAB decline. Consequently, microbial communities and the environment dynamically and complexly changed in A. sanguinea bloom, and a rapid turnover of microorganisms could respond to ecological interactions. Microbial communities in $\mathrm{HAB}$ ecology are composed of various organisms and they interact in a complex way. Therefore, to interpret their ecosystem, the complex reactions among various microorganisms should be studied rather than studying a simple 1:1 reaction, such as a prey-predator interaction.

\section{Methods}

\section{Sample collection}

The sampling site (Jangmok Bay Time-series Monitoring Site, JBTMS: $34^{\circ} 59^{\prime} 37^{\prime \prime} \mathrm{N}$ and $128^{\circ} 40^{\prime} 27^{\prime \prime}$ E) is a semi-closed bay on the southern coast of South Korea (Supplementary Fig. 7). The JBTMS is a eutrophic system that is subjected to strong mixing between the surface and bottom layers. Its maximum tidal range is approximately $2.2 \mathrm{~m}$, and the mean water depth at the sampling station is approximately $8.5 \mathrm{~m}$. A total of 90 sub-samples during June 2016 and June 2017 were obtained from surface water (sampling depth: $1 \mathrm{~m}$ under sea surface). In particular, when $A$. sanguinea bloomed (November $11^{\text {th }}$ to December $13^{\text {th }}$ 2016), sampling was performed daily. We also explored the differences between $A$. sanguinea bloom and no-bloom condition daily between November $14^{\text {th }}$ to December $13^{\text {th }} 2017$. We drew 20-L samples of seawater from the surface layer and stored them in a cooler until arrival ( $5 \mathrm{~min}$ ) at the laboratory of the South Sea Institute of Korea Institute of Ocean Science \& Technology (KIOST, Geoje, South Korea), where the seawater was prepared immediately.

\section{Monitoring of environmental factors}

Temperature, salinity, $\mathrm{pH}$, and dissolved oxygen were evaluated using a portable YSI environmental multiparameter (YSI 6920 Inc., Yellow Springs, OH, USA). A 100-mL aliquot of each sub-sample was filtered 
through a 47-mm glass fibre filter (GF/F, Whatman, Clifton, NJ, USA), and the filtered seawater was stored in an acid-cleaned polyethylene bottle in a deep freezer (at $-80^{\circ} \mathrm{C}$ ). Subsequently, concentrations of dissolved inorganic nutrients, such as inorganic nitrogen (DIN; $\mathrm{NO}_{2}{ }^{-}+\mathrm{NO}_{3}{ }^{-}+\mathrm{NH}_{4}{ }^{+}$), inorganic phosphorus (DIP), and silica (DSi) were determined in each sample using an automatic nutrient analyser (Quaatro39; Seal analytical instrument, UK). To analyse the dissolved organic carbon (DOC) concentration, a 10-mL aliquot of each water sample was filtered through the GF/F filter (pre-combusted at $450{ }^{\circ} \mathrm{C}$ overnight) under gravity pressure, and the DOC concentration was determined using a hightemperature catalytic combustion instrument ( $\mathrm{TOC}-\mathrm{V}_{\mathrm{CPH}}$; Shimadzu, Kyoto, Japan). To determine chlorophyll a concentration, $500 \mathrm{~mL}$ of each sample was filtered through the GF/F filter under low vacuum pressure. Each filter was soaked in $15 \mathrm{~mL}$ of cold $90 \%$ acetone-distilled water ( $\mathrm{v} / \mathrm{v})$ and sonicated to break the cell walls. Then, chlorophyll $a$ was extracted for $24 \mathrm{~h}$ at $4{ }^{\circ} \mathrm{C}$ in the dark, and its concentration was measured using a fluorometer (10-AU; Turner Designs, Inc., San Jose, CA, USA).

\section{Microscopic observation}

To count total heterotrophic bacteria, a $10-\mathrm{mL}$ aliquot was collected from each sub-sample in a $15-\mathrm{mL}$ sterilised polyethylene bottle and fixed immediately with glutaraldehyde (at a final concentration of $2 \%$ ). The sample was stored in the dark at $4{ }^{\circ} \mathrm{C}$ prior to analysis. The fixed bacterial cells were filtered through a black isopore membrane filter (GTBP 02500; Millipore, Bedford, MA, USA) and stained with $1 \mu \mathrm{g} \mathrm{mL}^{-1}$ of 4',6-diamidino-2-phenylinodole solution[48]. At least 600 stained bacterial cells per sample were counted using an epifluorescence microscope (Axioplan, Zeiss, Oberkochen, Germany) at a magnification of $1,000 \times$. To count and identify phytoplanktonic communities, at least 500 phytoplankton cells per subsample were identified and counted using a phytoplankton (or Sedgwick-Rafter) counting chamber under a light microscope (Axioplan) at a magnification of $400-1,000 \times$.

\section{Preparation for DNA extraction of microbial communities}

The microbial communities are multi-phylotype communities, ranging from the numerically dominant viruses to the phylogenetically diverse eukaryotic plankton. For mNGS, Flaviani et al.[22] concluded that $250 \mathrm{~mL}$ of seawater is sufficient to analyse microbial diversity (from double-stranded DNA virome to phytoplankton). Therefore, we analysed NCLDVs, bacteria, and eukaryotic planktonic organisms, including the endoparasitic dinoflagellate Amoebophrya spp., from $1 \mathrm{~L}$ surface seawater. Moreover, for analyses of various microbial communities, we harvested the microbes in three steps according to their size fraction; 1), a $10 \mu \mathrm{m}$ polycarbonate filter (TCTP04700, Millipore) was used, which focused on eukaryotic plankton and dinospores of Amoebophrya sp. in A. sanguinea cells at cell size of $>10 \mu \mathrm{m}$. To remove organisms $<10 \mu \mathrm{m}$ in size and particles attached to $A$. sanguinea cell surfaces, cells collected on the $10 \mu \mathrm{m}$ filter were washed three times with approximately $50 \mathrm{~mL}$ distilled water at approximately $50-60$ ${ }^{\circ} \mathrm{C}$. 2), a $3 \mu \mathrm{m}$ polycarbonate filter (TSTP04700) was used, which focused on free-living Amoebophrya spp. and nano-sized phytoplankton at cell size of $10-3 \mu \mathrm{m}$, and 3), a $0.22 \mu \mathrm{m}$ polycarbonate filter (GTTP04700) was used, which focused on bacteria and NCLDVs at cell size of 3-0.22 $\mu \mathrm{m}$. The filters were stored at $-80^{\circ} \mathrm{C}$ until DNA extraction. 


\section{mNGS analyses of bacteria and eukaryotic plankton}

The filters at each size fraction were cut into several pieces for genomic DNA (gDNA) extraction. To analyse the bacterial community in the water samples, gDNA was extracted using the DNeasy Powersoil Kit (Qiagen, Valencia, CA, USA) from the 3-0.22 $\mu \mathrm{m}$ size fraction; the DNA was diluted to a final concentration of $20 \mathrm{ng} \mathrm{LL}^{-1}$. The quantity and quality of the total gDNA was determined using Nano-drop (Nano-MD-NS, SCINCO Ltd., South Korea). The V3-V4 hyper variable regions of bacterial 16S rDNA genes were amplified using the universal Illumina tagged forward (341F) and reverse (800R) primers (Supplementary Table 10). To analyse eukaryotic plankton, gDNA was extracted from the $>10 \mu \mathrm{m}$ and 10-3 $\mu \mathrm{m}$ size fractions using a DNeasy PowerSoil kit; DNA was diluted to each final concentration of 30 $\mathrm{ng} \mu \mathrm{L}^{-1}$ and $20 \mathrm{ng} \mu \mathrm{L}^{-1}$, respectively. The V4-V5 region of the 18S rDNA gene was targeted using the Illumina tagged forward (TAReuk454FWD1) and reverse (TAReukREV3) primers (Supplementary Table 11). Although we did not perform replicate experiments, we attempted to overcome the experimental bias and obtain more accurate results as follows; 1 ), intensive daily continuous monitoring in JBTMS, 2), indoor microcosm experiments to verify changes in endoparasitic dinoflagellates and NCLDVs in the field, and 3) three PCRs performed in distinct tubes, and then mixing of the PCR reaction products to obtain more accurate mNGS results[49]. The amplified products from the first PCR were individually purified using a QIAquick PCR purification kit (Qiagen, Hilden, Germany). The second PCR lasted 10 cycles using tags of Nextera XT 96 index kit v2 (Illumina). DNA concentration was measured in a Bio-analyzer 2100 (Agilent Technologies, Palo Alto, CA, USA). Equal concentrations of the PCR products for each sample were pooled, and the merged samples were analysed using a Mi-Seq platform (Illumina, San Diego, CA, USA).

After each sequencing procedure was completed, the data were pre-processed using Mi-Seq Control Software (MCS) v2.4.1. Raw sequences were first analysed using FastQC[50] to check basic statistics, such as GC \%. Furthermore, quality score distribution per base, and poor-quality sequences were flagged. Additionally, ambiguous and chimeric reads were removed, and the noised sequences (denoising), which involved OTUs with 1, 2, and 3 reads, were removed at a cut-off of $97 \%$. The processed pair-end reads were then merged using the fast length adjustment of short reads (FLASH) software tool[51]. After each sequencing procedure, a quality check was performed to remove short sequence reads ( $<150 \mathrm{bp}$ ), lowquality sequences (score $<25$ in analysis of $16 \mathrm{~s}$ rDNA; score $<33$ in analysis of $18 \mathrm{~s}$ rDNA), singletons, and non-target sequences. Using Basic Local Alignment Search Tool (BLAST)[52], all the sequence reads were compared with those from the National Center for Biotechnology Information (NCBI) database. Sequence reads with an E-value smaller than 0.01 were considered for further analysis. A pairwise global alignment was performed on the selected candidate hits to identify the most similar sequences. The taxonomy of the sequence with the highest similarity was assigned to the sequence read (species or genus levels with $>97 \%$ or $>94 \%$ similarity, respectively). To analyse operational taxonomic units (OTUs), the CD-HIT-OTU software[53] was used for clustering and metagenomic functional information. To calculate alpha-diversity, including Shannon-Weaver diversity, Chao richness, and Simpson evenness, we used the closed-reference protocol published by Mothur[54] and QIIME[55] based on the OTU table. 


\section{mNGS analysis of Nucleo Cytoplasmic Large DNA Viruses}

To analyse NCLDVs, gDNA was used of extracted it for analysis of bacterial metagenomics, and sequencing library of NCLDVs was generated using NEBNext Ultra DNA Library Prep Kit (Illumina, San Diego, USA) following the manufacturer's instructions. The library was prepared by random fragmentation of the DNA sample, followed by 5' and 3' adapter ligation. "Tagmentation", which combines the fragmentation and ligation reactions into a single step and greatly increases the efficiency of library preparation, was used. Adapter-ligated fragments were then amplified using 12 PCR cycles and purified by gel electrophoresis and a gel extraction kit (Qiagen, Hilden, Germany). Libraries were analysed for size distribution by using a Bio-analyser 2100 model (Agilent Technologies, Palo Alto, CA, USA), which indicated that the final library contained inserts between 35 and 1,000 base pairs[56]. Clustering of the index-coded samples was performed on a cBot Cluster Generation System according to the manufacturer's instructions. After cluster generation, the library preparations were sequenced on an Illumina Hi-Seq 2500 platform (Illumina, San Diego, CA, USA).

FASTAQ files were imported into the CLC Genomics Workbench v. 11.0.1 (Qiagen, Hilden, Germany). Reads below 0.05 quality score cut-off and adapter trimming were removed from subsequent analyses. The remaining reads were trimmed of any ambiguous and low quality 5 ' bases, and only reads at the full length were retained for assembly. Quality controlled reads were then de novo assembled using the assemble function (minimum $>300 \mathrm{bp}$ ) of the CLC Genomics Workbench for ambiguous nucleotide trimming and bad reads filtered at the limit of Q20. To identify viruses, the assembled contigs were subjected to a BLAST search against viral reference genome sequences, using the NCBI virus genome database (http://www.ncbi.nlm.nih.gov/genome/viruses/) for taxonomic assignment using BLASTX (Evalue $\left.<10^{-5}\right)$.

\section{Indoor microcosm experiment}

To investigate the changes in environmental factors, and the potential biological control mechanisms of A. sanguinea bloom, we conducted 100-L in-door microcosm experiments (Supplementary Fig. 8)[23]. The experiment included three enclosures (triplicate experiments), each containing $80 \mathrm{~L}$ of seawater when natural $A$. sanguinea bloomed at a mean density of 920 cells $\mathrm{mL}^{-1}$. Each microcosm was a $100 \mathrm{~L}$ enclosure within a cylinder of transparent acrylic material. To observe the survival and growth of $A$. sanguinea cells in terms of changes in the water temperature, the room temperature was maintained at an average of $18{ }^{\circ} \mathrm{C}$ for the first three days and sustained at $15^{\circ} \mathrm{C}$ for the last period of the experiment. Light intensity was $50 \mathrm{E} \mathrm{m}^{-2} \mathrm{~s}^{-1}$ under a $16 \mathrm{~h} \mathrm{:} 8 \mathrm{~h}$ (light : dark) cycle. Water in each microcosm was mixed by three impellers (each $15 \mathrm{~cm}$ long and $6 \mathrm{~cm}$ wide) at a speed of $10 \mathrm{rpm}$ on a $15 \mathrm{~min}: 15 \mathrm{~min}$ automatically controlled run : stop cycle. The experiment lasted 22 days. During this time, we collected 17 sub-samples (daily collection for 12 days and bi-daily collection the last 10 days) for analysis of environmental factors and microbial communities.

\section{Statistical interpretation of the data}


Pearson's correlation analysis was performed to examine the relationships between the measured parameters using SPSS v.12 (SAS Institute Inc., Cary, NC, USA). Cluster analysis was performed using group average clustering by the Bray-Curtis similarity method on the most abundant OTUs of bacteria and NCLDVs (over $1 \%$ in at least one sample). Using the ranked similarity matrix, an ordination plot was produced by non-metric multidimensional scaling (nMDS) using PRIMER 6 (version 6.1.13). Hierarchical agglomerative clustering using the group average method was carried out on the most abundant OTUs based on groups selected from nMDS analysis. To test the null hypothesis (no significant difference between the groups discriminated according to the agglomerative clustering analysis), similarities were analysed with ANOSIM in PRIMER[57].

Extended local similarity Aanalysis (eLSA)[58] was used for data of 2016 and 2017 with 33 and 29 days, respectively, (a time interval of two days) to analyse covariation between the most abundant OTUs, each displaying a relative abundance $>1 \%$ in at least one sample, resulting in 63 and 76 OTUs of microbial communities and 9 environmental parameters each in 2016 and 2017, respectively. P-value was determined using statistical approximation followed by permutation testing to reduce computing time, and ensuring accuracy and Q-value (false discovery rate) was calculated to estimate the likelihood of false positives[59]. eLSA network of delay-shifted Spearman correlation coefficients (SCC) between variables was visualized using Cytoscape v3.7.2[60] with $P<0.01$ and $Q<0.05$. Because the sampling was evenly spaced for two-day intervals, maximum time-lags were considered to be 10 days. The networks were selected by $A$. sanguinea identification or edge type (or example, correlations between specific OTUs). Random undirected networks of equal size by number of nodes and edges were calculated by the Erdös-Rényi model using the Random Network plugin in Cytoscape. Network statistics were calculated with the network analyzer as undirected networks using the defaults[61].

\section{Declarations}

\section{Availability of data and materials}

The raw sequencing data (Fastaq files) of 16s rDNA and 18s rDNA genes obtained from the Mi-Seq platform were deposited in the Sequence Read Archive database at NCBI under accession numbers: SRR11123089-11123163 (PRJNA 607609), SRR11136919-11136959 (PRJNA 607810), and SRR11131500-11131531 (PRJNA 607814). The raw sequencing files of NCLDVs obtained from the HiSeq platform were deposited in the Sequence Read Archive database at NCBI under accession number SRR11172603-11172644 (PRJNA 608210).

\section{Acknowledgements}

The stored gDNA samples and fixed phytoplankton samples were obtained from the Library of Marine Samples, Korea Institute of Ocean Science \& Technology, South Korea.

\section{Funding}


This research was supported by the National Research Foundation (NRF) funded by the Ministry of Science and ICT (MSIT) (NRF-2020R1A2C2005970) and (NRF-2017M3A9E4072753).

\section{Author Information}

\section{Contributions}

Jung S.W., Park P., and Lee T.K. designed the research plan; Jung S.W., Park J., Kang J., Kim H.-J., Joo H.M., Seo H., Kim S., and Jang M.C. performed the experiments; Jung S.W., Park J., Kang J., Joo H.M., Kang D., Jang M.C., Lee K., Oh S.J., Lee S., and Lee T.K. discussed the results; Jung S.W., Park J., Kang J., Kim H.-J., Joo H.M., Kang D., Lee K., Oh S.J., and Lee T.K. wrote the paper.

\section{Ethics declarations}

\section{Ethics approval and consent to participate}

Not applicable

\section{Consent for publication}

Not applicable

\section{Competing interests}

There are no conflicts of interests to declare.

\section{References}

1. Zhou J, Ricklen MI, Sehein TR, Kulis DM, Anderson DM, Cai Z. Microbial community structure and associations during a marine dinoflagellate bloom. Front Microbiol. 2018;9:1201.

2. Arrigo KR. Marine microorganisms and global nutrient cycles. Nature. 2005;437:349-355.

3. Anderson DM. Turning back the harmful red tide. Nature. 1997;388:513-514.

4. Smayda TJ. Harmful algal blooms: their ecophysiology and general relevance to phytoplankton blooms in the sea. Limnol Oceanogr. 1997;42:1137-1153.

5. Yang C, Li Y, Zhou Y, Zheng W, Tian Y, Zheng T. Bacterial community dynamics during a bloom caused by Akashiwo sanguinea in the Xiamen sea area, China. Harmful Algae. 2012;20:132-141.

6. Du X, Peterson W, McCulloch A, Liu G. An unusual bloom of the dinoflagellate Akashiwo sanguinea off the central Oregon, USA, coast in autumn 2009. Harmful Algae. 2011;10:784-793.

7. Jessup DA, Miller MA, Ryan JP, Nevins HM, Kerkering HA, Mekebri A et al. Mass Stranding of marine birds Caused by a surfactant-producing red tide. PLos ONE. 2009;4:e4550.

8. Reis-Filho JA, da Silva EM, Nunes JACC, Barros F. Effects of a red tide on the structure of estuarine fish assemblages in northeastern Brazil. Internat. Rev Hydrobiol. 2012;97:389-404. 
9. Chen T, Liu Y, Song S, Li C. Characterization of the Parasitic Dinoflagellate Amoebophrya sp. Infecting Akashiwo sanguinea in Coastal Waters of China. J Eukaryot Microbiol. 2018;65:448-457.

10. Fuhrmanl JA. Marine viruses and their biogeochemical and ecological effects. Nature. 1999;399:541-548.

11. Colson P, De Lamballerie X, Yutin N, Asgari S, Bigot Y, Bideshi DK et al. "Megavirales", a proposed new order for eukaryotic nucleocytoplasmic large DNA viruses. Arch Virol. 2013;158:2517-2521.

12. Van Etten JL, Graves MV, Muller DG, Boland W, Delaroque N. Phycodnaviridae-large DNA algal viruses. Arch Virol. 2002;147:1479-1516.

13. Claverie JM, Abergel C. Mimiviridae: An Expanding Family of Highly Diverse Large dsDNA Viruses Infecting a Wide Phylogenetic Range of Aquatic Eukaryotes. Viruses. 2018;10:506.

14. Schulz F, Yutin N, Ivanova NN, Ortega DR, Lee TK, Vierheilig J, Daims H. Giant viruses with an expanded complement of translation system components. Science. 2017;356:82-85.

15. Azam F, Malfatti F. Microbial structuring of marine ecosystems. Nat Rev Microbiol. 2007;5:782-791.

16. Worden AZ, Follows MJ, Giovannoni SJ, Wilken S, Zimmerman AE, Keeling PJ. Environmental science. Rethinking the marine carbon cycle: factoring in the multifarious lifestyles of microbes. Science. 2015;347:1257594.

17. Yang $C$, Li Y, Zhou Y, Lei $X$, Zheng W, Tian $Y$ et al. A comprehensive insight into functional profiles of free-living microbial community responses to a toxic Akashiwo sanguinea bloom. Scientific Reports. 2016;6:34645.

18. Mazzillo FFM, Ryan JP, Silver MW. Parasitism as a biological control agent of dinoflagellate blooms in the California current system. Harmful Algae. 2011;10:763-773.

19. Coats DW, Park MG. Parasitism of photosynthetic dinoflagellates by three strains of Amoebophrya (Dinophyta): parasite survival, infectivity, generation time, and host specificity. J Phycol. 2002;38:520-528.

20. Coats DW, Adam EJ, Gallegos CL, Hedrick S. Parasitism of photosynthetic dinoflagellates in a shallow subestuary of Chesapeake Bay, USA. Aquat Microb Ecol. 1996;11:1-9.

21. Kim HJ, Jung SW, Lim DI, Jang MC, Lee TK, Shin K, Ki JS. Effects of temperature and nutrients on changes in genetic diversity of bacterioplankton communities in a semi-closed bay, South Korea. Mar Pollut Bull. 2016;106:139-148.

22. Flaviani F, Schroeder DC, Balestreri C, Schroeder JL, Moore K, Paszkiewicz K et al. A pelagic microbiome (Viruses to Protists) from a small cup of seawater. Viruses. 2017;9:47.

23. Jung SW, Noh SY, Kang D, Lee TK. Comparison of bacterioplankton communities between before and after inoculation with an algicidal material, Ca-aminoclay, to mitigate Cochlodinium polykrikoides blooms: assessment using microcosm experiments. J Appl Phycol. 2017;29:1343-1354.

24. Pakulski JD, Benner R. Abundance and distribution of carbohydrate in the ocean. Limnol Oceanogr. 1994;39:930-940. 
25. Børsheim KY, Myklestad SM, Sneli JA. Monthly profiles of DOC, mono-and polysaccharides at two locations in the Trondheimsfjord (Norway) during two years. Mar Chem. 1999;63:255-272.

26. Fajon C, Cauwet G, Lebaron P, Terzic S, Ahel M, Malej A, et al. The accumulation and release of polysaccharides by planktonic cells and the subsequent bacterial response during a controlled experiment. FEMS Microbiol Ecol. 1999;29:351-363.

27. Myklestad S. Release of extracellular products by phytoplankton with special emphasis on polysaccharides. Sci Total Environ. 1995;165:155-164.

28. Chen W, Wangersky PJ. Rates of microbial degradation of dissolved organic carbon from phytoplankton cultures. J Plankton Res. 1996;18:1521-1533.

29. Penna A, Berluti S, Penna N, Magnani M. Influence of nutrient ratios on the in vitro extracellular polysaccharide production by marine diatoms from the Adriatic Sea. J Plankton Res. 1999;21:16811690.

30. Urbani R, Magaletti E, Sist P, Cicero AM. Extracellular carbohydrates released by the marine diatoms Cylindrotheca closterium, Thalassiosira pseudonana and Skeletonema costatum: Effect of Pdepletion and growth status. Sci Total Environ. 2005;353:300-306.

31. Matsubara T, Nagasoe S, Yamasaki Y, Shikata T, Shimasaki Y, Oshima Y, Honjo T. Effects of temperature, salinity, and irradiance on the growth of the dinoflagellate Akashiwo sanguinea. $J$ Exp Mar Biol Ecol. 2007; 342:226-230.

32. Croft MT, Lawrence AD, Raux-Deery E, Warren MJ, Smith AG. Algae acquire vitamin B12 through a symbiotic relationship with bacteria. Nature. 2005;438:90-93.

33. Naviner M, Bergé JP, Durand P, Le Bris H. Antibacterial activity of the marine diatom Skeletonema costatum against aquacultural pathogens. Aquaculture. 1999;174:15-24.

34. Sapp M, Schwaderer AS, Wiltshire KH, Hoppe HG, Gerdts G, Wichels A. Species-Specific Bacterial Communities in the Phycosphere of Microalgae? Microb Ecol. 2007;53:683-699.

35. Jung SW, Kim BH, Katano T, Kong DS, Han MS. Pseudomonas fluorescens HYK0210-SK09 offers species specific biological control of winter algal blooms caused by freshwater diatom Stephanodiscus hantzschii. J Appl Microbiol. 2008;105:186-195.

36. Mayali X, Azam F. Algicidal bacteria in the sea and their impact on algal blooms. J Eukaryot Microbiol. 2004;51:139-144.

37. Philippe N, Legendre M, Doutre G, Poirot O, Lescot M, Arslan D et al. Pandoraviruses: Amoeba Viruses with Genomes Up to 2.5 Mb Reaching That of Parasitic Eukaryotes. Science. 2013;341:281-286.

38. Yutin N, Koonin EV. Pandoraviruses are highly derived phycodnaviruses. Biol Direct. 2013;8:25.

39. Legendre M, Fabre E, Poirot O, Jeudy S, Alempic JM, Beucher L et al. Diversity and evolution of the emerging Pandoraviridae family. Nat Commun. 2018;9:2285.

40. Winter C, Bouvier T, Weinbauer MG, Thingstad TF. Trade-Offs between Competition and Defense Specialists among Unicellular Planktonic Organisms: the "Killing the Winner" Hypothesis Revisited. Microbiol Mol Biol R. 2010;74:42-57. 
41. Silveira CB, Rohwer FL. Piggyback-the-Winner in host-associated microbial communities. NPJ J Biofilms Microbl. 2016;2:16010.

42. Chambouvet A, Morin P, Marie D, Guillou L. Control of toxic marine dinoflagellate blooms by serial parasitic killers. Science. 2008;322:1254-1257.

43. Chambouvet A, Laabir M, Sengco M, Vaquer A, Guillou L. Genetic diversity of Amoebophryidae (Syndiniales) during Alexandrium catenella/tamarense (Dinophyceae) blooms in the Thau lagoon (Mediterranean Sea, France). Res Microbiol. 2011;162:959-968.

44. Lima-Mendez G, Faust K, Henry N, Decelle J, Colin S, Carcillo F et al. Determinants of community structure in the global plankton interactome. Science. 2015;348:1262073.

45. Montagnes DJS, Chambouvet A, Guillou L, Fenton A. Responsibility of microzooplankton and parasite pressure for the demise of toxic dinoflagellate blooms. Aquat Microb Ecol. 2008;53:211225.

46. Eiler A, Heinrich F, Bertilsson S. Coherent dynamics and association networks among lake bacterioplankton taxa. ISME J. 2012;6:330-342.

47. Fuhrman JA, Steele JA. Community structure of marine bacterioplankton: patterns, networks, and relationships to function. Aquat Microb Ecol. 2008;53:69-81.

48. Porter KG, Feig YS. The use of DAPI for identification and counting aquatic microflora. Limnol Oceanogr. 1980;25:943-948.

49. Jung SW, Kang D, Kim HY, Shin HH, Park JS, Park SY, Lee TK. Mapping distribution of cysts of recent dinoflagellate and Cochlodinium polykrikoides using next-generation sequencing and morphological approaches in South Sea, Korea. Scientific Reports. 2018;7:7011.

50. Andrews S. FQC A quality control tool for high throughput sequence data. 2010; http://www.bioinformatics.babraham.ac.uk/projects/ fastqc.

51. Magoč T, Salzberg SL. FLASH: fast length adjustment of short reads to improve genome assemblies. Bioinformatics. 2011;27:2957-2963.

52. Altschul SF, Gish W, Miller W, Myers EW, Lipman DJ. Basic local alignment search tool. J Mol Biol. 1990;215:403-410.

53. Li RW, Connor EE, Li C, Baldwin VIRL, Sparks ME. Characterization of the rumen microbiota of preruminant calves using metagenomic tools. Environ Microbiol. 2012;14:129-139.

54. Schloss PD, Westcott SL, Ryabin T, Hall JR, Hartmann M, Hollister EB. Introducing mothur: opensource, platform-independent, community-supported software for describing and comparing microbial communities. Appl Environ Microb. 2009;75:7537-7541.

55. Caporaso JG, Kuczynski J, Stombaugh J, Bittinger K, Bushman FD, Costello EK et al. QIIME allows analysis of high-throughput community sequencing data. Nat methods. 2010;7:335-336.

56. Hwang J, Park SY, Lee S, Lee TK. High diversity and potential translocation of DNA viruses in ballast water. Mar Poll Bull. 2018;137:449-455. 
57. Clarke KR. Non-parametric multivariate analyses of changes in community structure. Aust $J$ Ecol. 1993;18:117-43.

58. Xia LC, Steele JA, Cram JA, Cardon ZG, Simmons SL, Vallino JJ, et al. Extended local similarity analysis (eLSA) of microbial community and other time series data with replicates. BMC Syst Biol. 2011;5:S15.

59. Xia LC, Ai D, Cram JA, Fuhrman JA, Sun F. Efficient statistical significance approximation for local similarity analysis of highthroughput time series data. Bioinformatics. 2013;29:230-237.

60. Shannon P, Markiel A, Ozier O, Baliga NS, Wang JT, Ramage D, et al. Cytoscape: a software environment for integrated models of biomolecular interaction networks. Genome Res. 2003;13:2498-2504.

61. Assenov Y, Ramírez F, Schelhorn S, Lengauer T, Albrecht M. Computing topological parameters of biological networks. Bioinformatics. 2008;24:282-284.

\section{Figures}



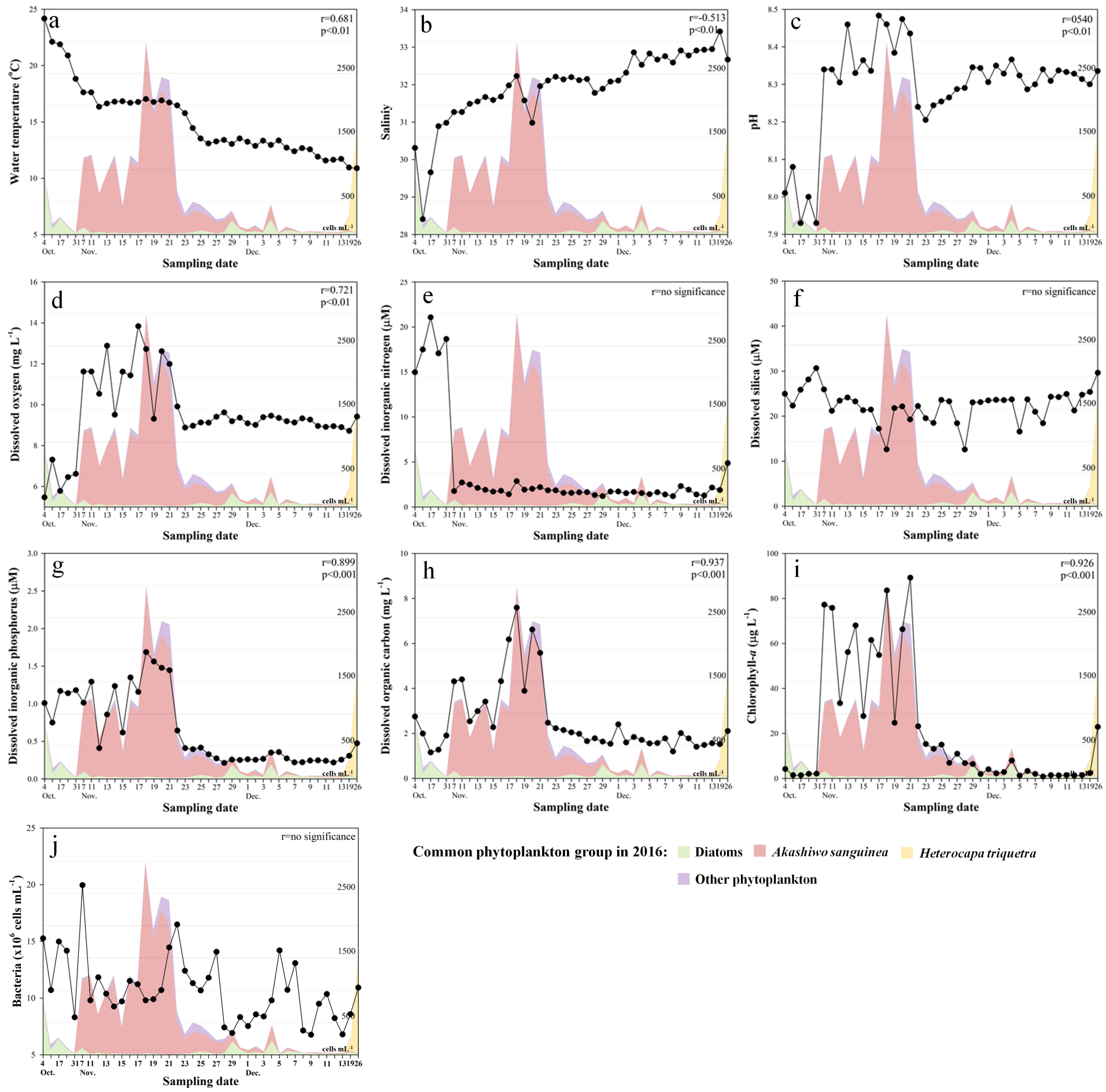

Common phytoplankton group in 2016: Diatoms Akashiwo sanguinea Heterocapatriquetra Other phytoplankton

\section{Figure 1}

Daily changes in environmental factors before, during, and after Akashiwo sanguinea bloom periods in 2016. a, water temperature; $b$, salinity; c, pH; d, dissolved oxygen; e, dissolved inorganic nitrogen; $f$, dissolved silica; $\mathrm{g}$, dissolved inorganic phosphorus; $\mathrm{h}$, dissolved organic carbon; $\mathrm{i}$, chlorophyll a; $\mathrm{j}$, total bacterial abundance. Coloured areas in the figure correspond to the common phytoplankton groups in 2016. $r$ value in each figure (upper right) indicates Pearson correlation coefficient between each environmental factor and A. sanguinea abundance. 

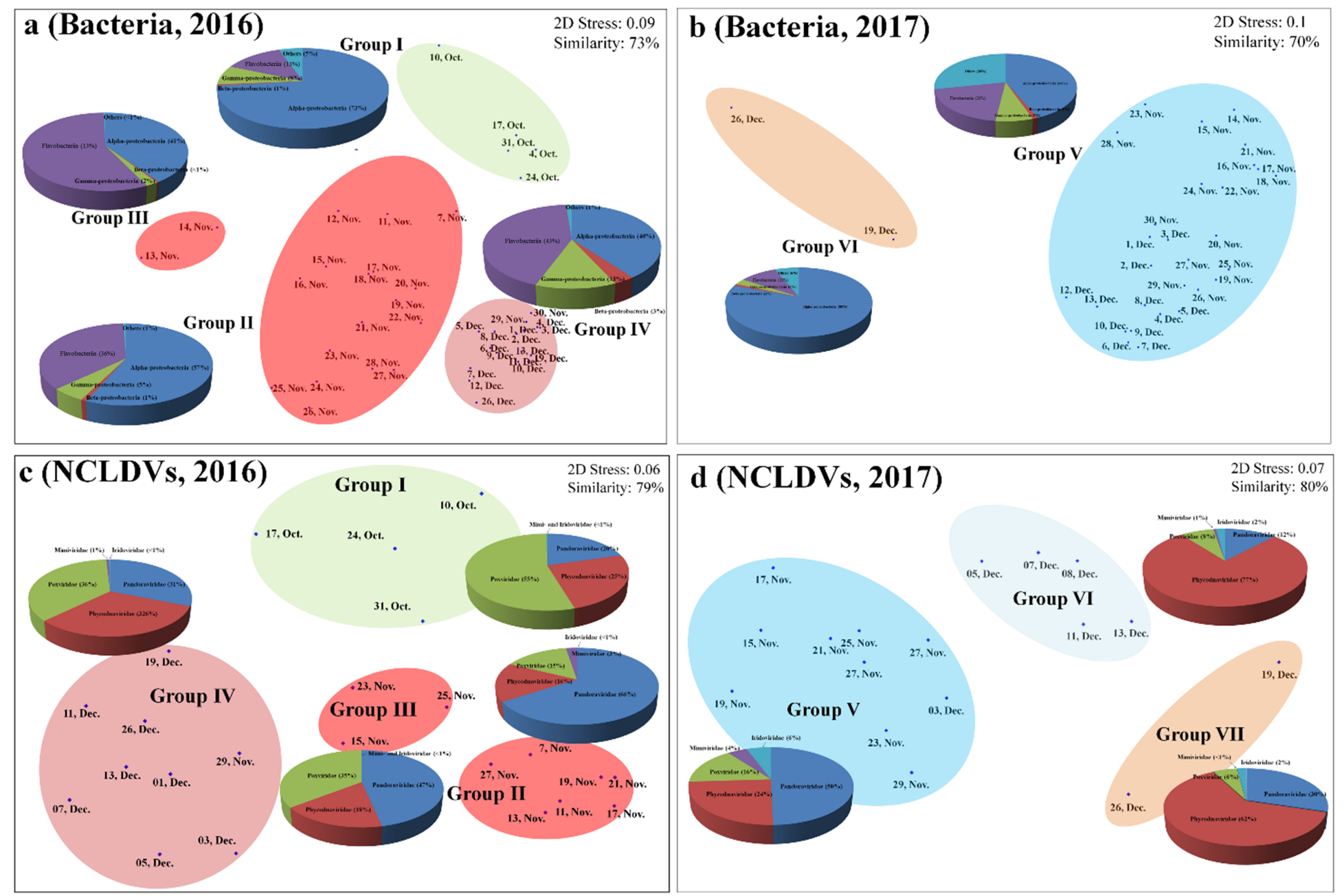

\section{Figure 2}

Non-metric multidimensional scaling (nMDS) plot by the Bray-Curtis dissimilarity method of bacterial community operational taxonomic units (OTUs) in 2016 (a, similarity: 73 \%) and 2017 (b, similarity: 70 \%). nMDS plot of Nucleo Cytoplasmic Large DNA Viruses (NCLDVs) OTUs in 2016 (c, similarity: 79 \%) and 2017 (d, similarity: $80 \%$ ). The coloured areas indicate the statistically supported groups by nMDS analysis, to facilitate the rapid identification of samples. The pie chart plots indicate high-ranking taxonomy distribution of the class level of bacteria community and family level of NCLDVs. 


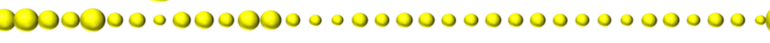

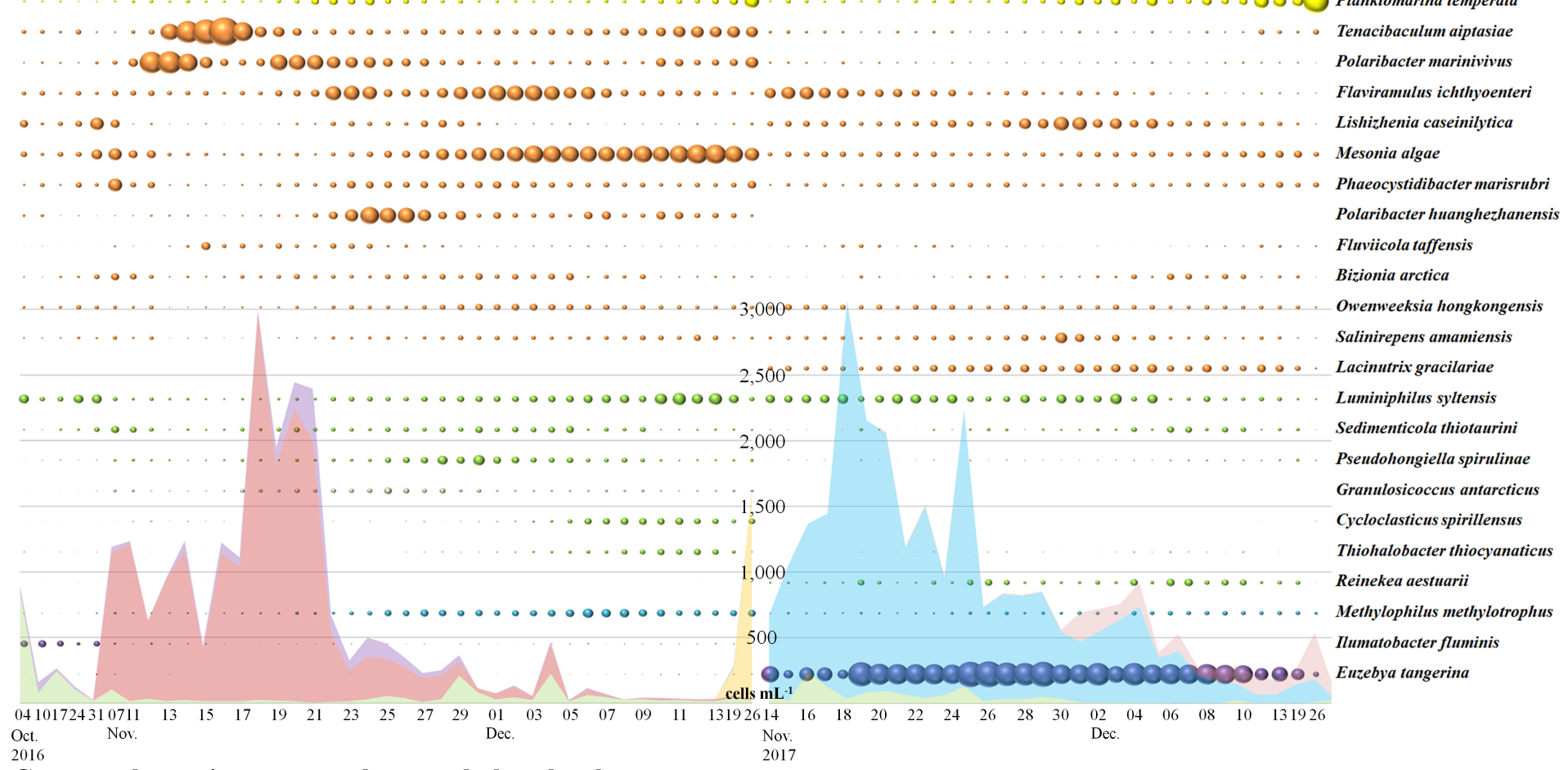

Common bacteria group at class or phylum levels

Alpha-proteobacteria Flavobacteriia Gamma-proteobacteria $\bigcirc$ Beta-proteobacteria $\bigcirc$ Actinobacteria

\section{Relative abundance (\%) of bacterial OTUs $100 \quad 50 \quad \bullet 10 \cdot 1$}

\section{Common phytoplankton group}

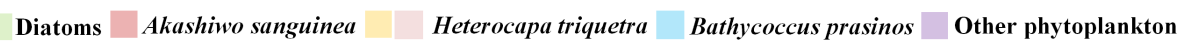

\section{Figure 3}

Time series circle plot showing the most abundant bacterial operational taxonomic units (OTUs) (each displaying a relative abundance $>1 \%$ in at least one sample) in 2016 and 2017. The colours in circle plots correspond to the common bacterial groups. The coloured areas correspond to the common phytoplankton groups in 2016 and 2017. To show the differences in relative abundance for the displayed OTUs, the circle is on a $0-100$ scale representing relative abundance (\%). 

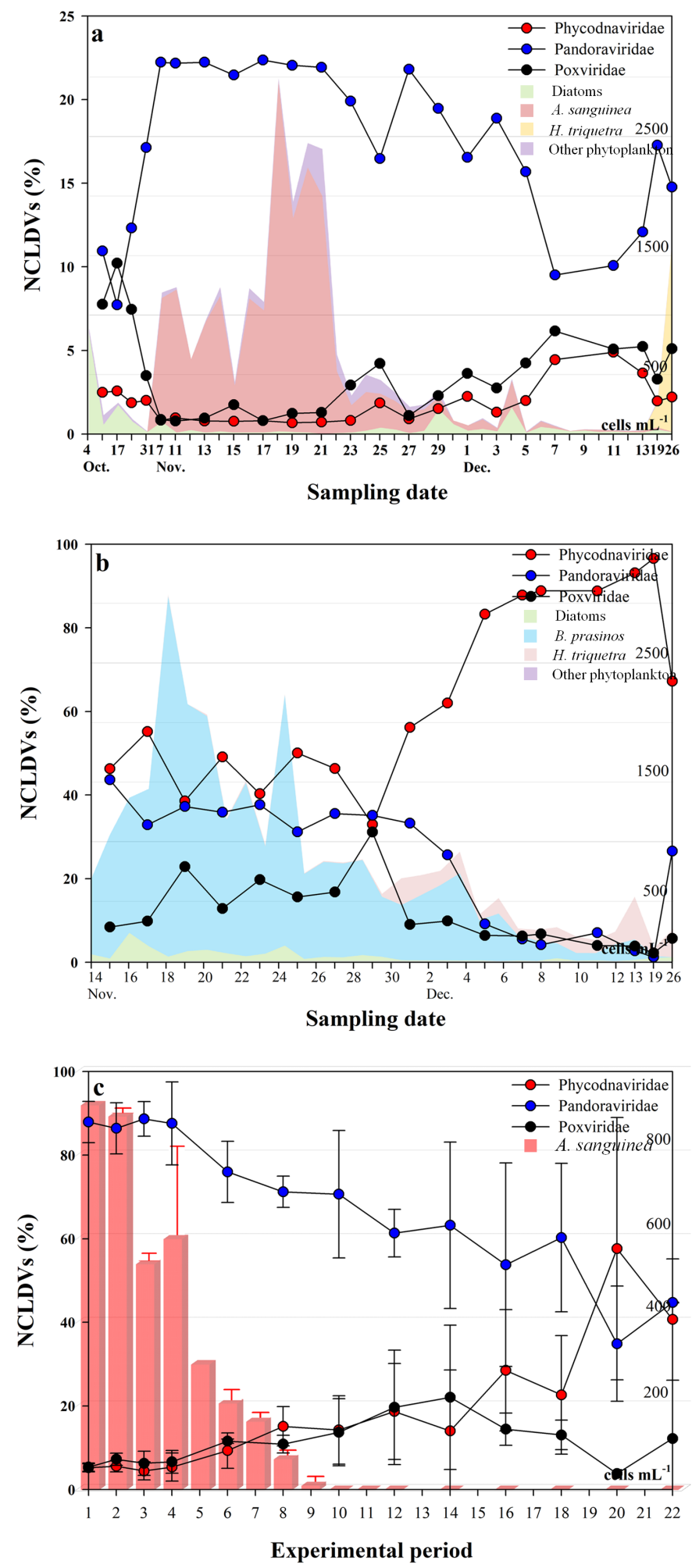

\section{Figure 4}

Daily changes in the most abundant Nucleo-Cytoplasmic Large DNA Viruses (NCLDVs) at family level (displaying a relative mean abundance $>1 \%$ ) during Akashiwo sanguinea bloom in 2016 (a), pico-sized green alga dominance, Bathycoccus prasinos (no A. sanguinea bloom), in 2017 (b) and in-door microcosm experiment. The coloured areas in the figure $4 \mathrm{a}$ and $4 \mathrm{~b}$ correspond to the common phytoplankton groups in 2016 and 2017, respectively. The red-coloured bar in the figure 4c is represented 
as a mean value (triplicate experiments) of A. sanguinea abundance and error bar indicates standard deviation.
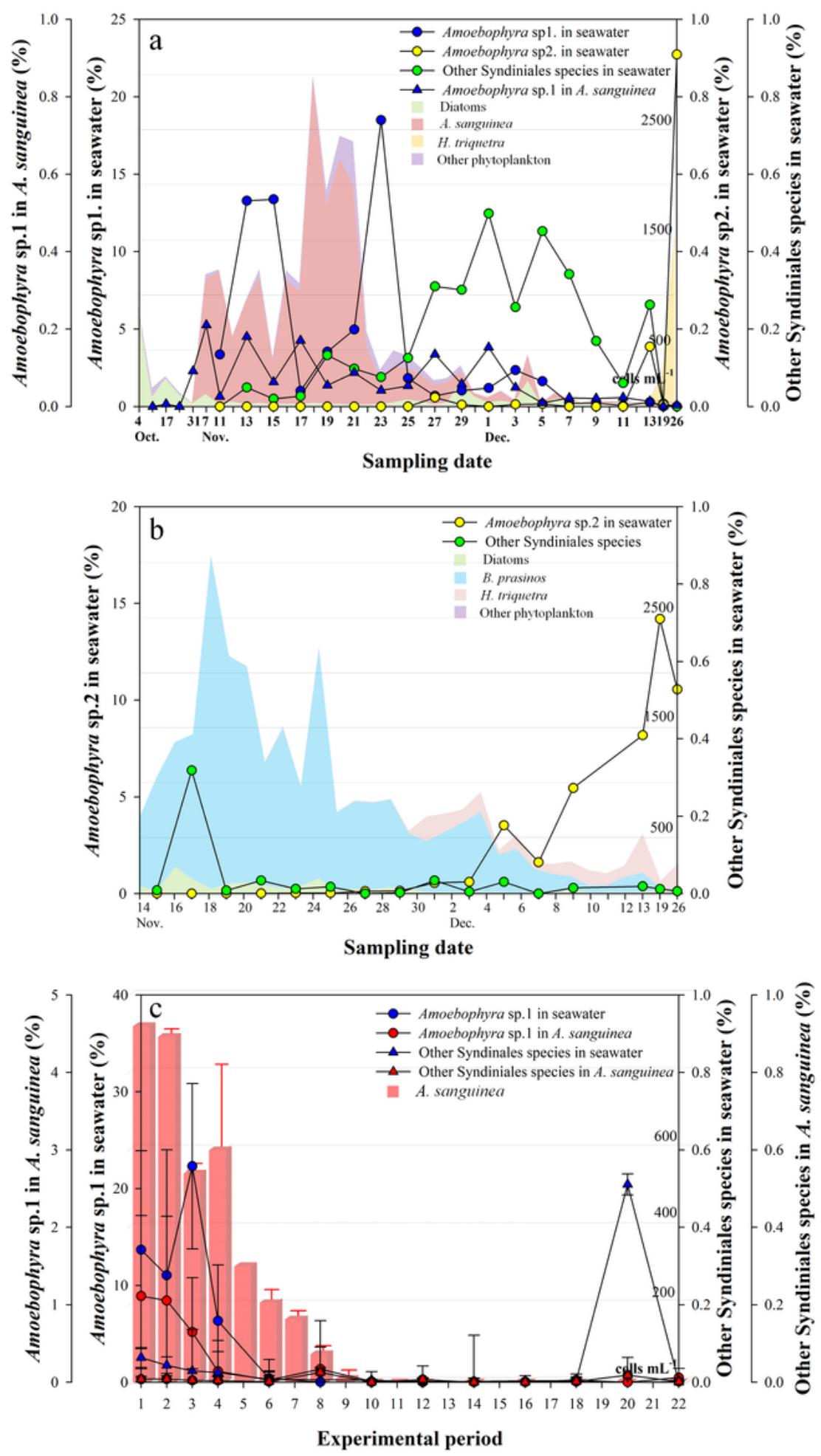

Figure 5

Daily changes in operational taxonomic units (OTUs) of endoparasitic dinoflagellate, Amoebophrya spp. (displaying a relative abundance) during Akashiwo sanguinea bloom in 2016 (a), pico-sized green alga dominance, Bathycoccus prasinos (no A. sanguinea bloom), in 2017 (b) and in in-door microcosm 
experiment (c). Amoebophrya spp. are mostly divided in Amoebophrya sp. 1, sp. 2, and other Syndiniales species. The coloured areas in the figure $4 \mathrm{a}$ and $4 \mathrm{~b}$ correspond to the common phytoplankton groups in 2016 and 2017, respectively. The red-coloured bar in the figure 4c is represented as a mean value (triplicate experiments) of A. sanguinea abundance and error bar indicates standard deviation.
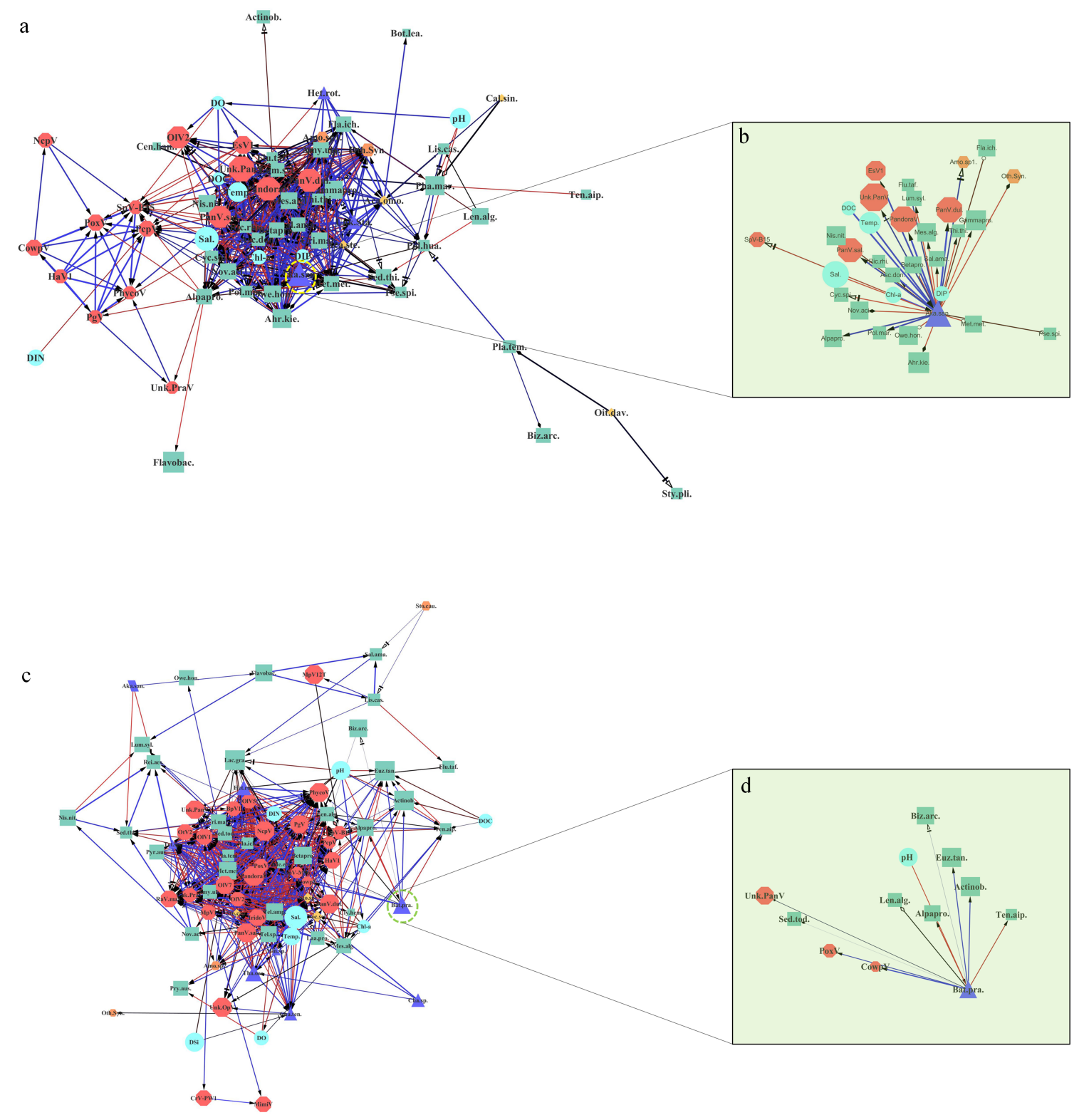

Node shape and color

$>$ Heterotroph $\triangle$ Autotroph Endoparasitic dinoflagellate $\square$ Bacteria $\bigcirc$ Nucleo Cytoplasmic Large DNA Virus $\bigcirc$ Environmental factor

Node size (Normalized scale) •

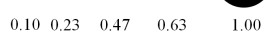

Target arrow shape (Time lag)

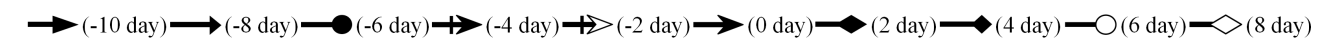

Edge color (Spearman Correlation Coefficient) Edge width (Spearman Correlation Coefficient)

\section{1} 0.000

$\overline{ \pm 0.250} \overline{ \pm 0.500} \frac{}{ \pm 0.750} \overline{ \pm 1.000}$

\section{Figure 6}


Network analysis derived from the most abundant operational taxonomic units (OTUs) and environmental factors showing only statistically significant correlations between OTUs and environmental factors (Spearman correlation coefficient $\geq 0.5$; $p<0.01$; false discovery $q<0.05$ ) in 2016 (a), sub-network associated with Akashiwo sanguinea (b) and in 2017 (c), and sub-network associated with Bathycoccus prasinos (d).

Before $A$. sanguinea bloom

During A. sanguinea bloom

After A. sanguinea bloom

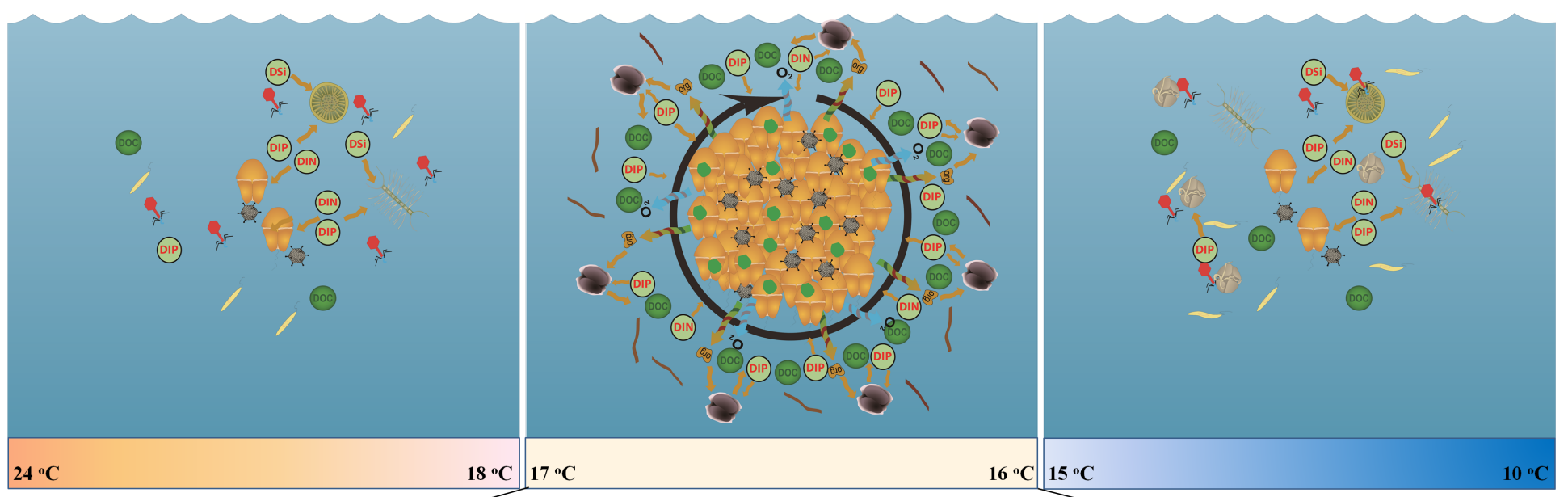

Key changes in specific environmental factors

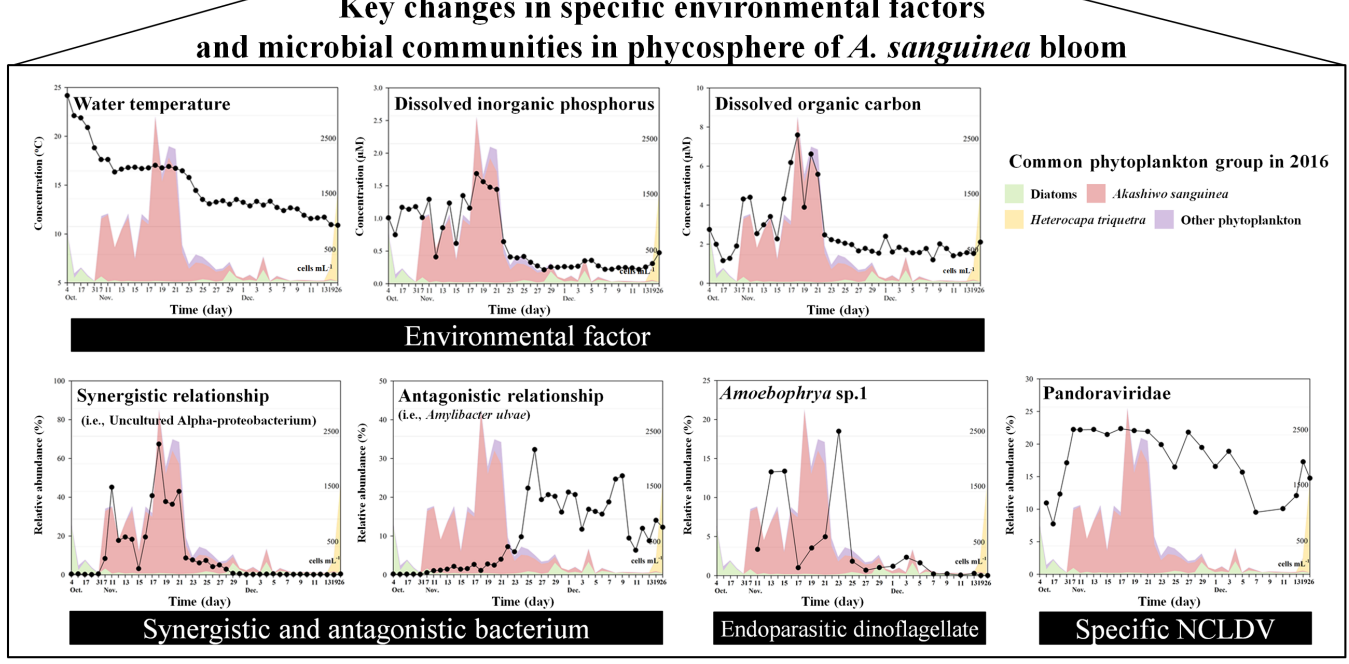

Microbial communities

Phytoplankton: Akashiwo sanguinea $\triangle$ Diatoms 0 Other dinoflagellate $\quad$ Endoparasitic dinoflagellate: $\backslash$ Amoebophrya sp. $\therefore$ Dinospores of Amoebophrya sp. Bacteria: Alpha-proteobacteria Flavobacteriales Gamma-proteobacteria

Nucleo-Cytoplasmic Large DNA Viruses (NCLDVs): Pandoraviridae Other NCLDVs (including Phycodnaviridae and Poxviridae)

\section{Biological Process}

6) Dissolved carbonate (DCHO) release by Akashiwo sanguinea $\bigcirc$ Akashiwo sanguinea bloom $I S$ Process in and out $0^{\mathrm{N}}$

\section{Figure 7}

Conceptual schematic diagram of the changes in environmental factors and specific microbial communities in phycosphere of Akashiwo sanguinea (Dinophyta) blooms. Three stages of interactions between environmental factors and microbial communities in A. sanguinea bloom. The first step is "before A. sanguinea bloom", the second is "during A. sanguinea bloom", and the last is "after A. sanguinea bloom”. Each step is introduced under different ecosystem scenarios. In particular, key 
changes in specific environmental factors and microbial communities in A. sanguinea bloom are introduced in the second step.

\section{Supplementary Files}

This is a list of supplementary files associated with this preprint. Click to download.

- SIJungetal.docx 